\title{
Relações entre saúde e trabalho docente: percepções de professores sobre saúde vocal
}

\author{
Relationships between health and teaching: teachers' perceptions \\ about vocal health
}

\author{
Regina Zanella Penteado ${ }^{1}$
}

\begin{abstract}
RESUMO
Objetivo: Conhecer percepções de professores acerca do processo saúde-doença relacionado à voz. Métodos: Foi realizada uma pesquisa qualitativa, que emprega o grupo focal para a coleta de dados e a análise de conteúdo para a organização das percepções dos professores em conjuntos temáticos. Resultados: Foram identificados quatro conjuntos temáticos: conhecimento e cuidados, preocupações e representações, identificação dos problemas e maneiras de enfrentá-los. Conclusões: O estudo põe em questão as tradicionais ações educativas em saúde vocal e confirma a necessidade de os profissionais envolvidos com a promoção da saúde docente assumirem a saúde como um recurso aplicado à vida das pessoas. Eles devem ampliar seus objetivos e focos de ação, incluindo questões da organização do trabalho e vida cotidiana, subjetividade e qualidade de vida, para melhor responderem às necessidades e maneiras de o professor perceber e lidar com o processo saúde-doença.
\end{abstract}

DESCRITORES: Promoção da saúde; Educação em saúde; Saúde escolar; Voz; Qualidade da voz; Distúrbios da voz

\section{INTRODUÇÃO}

A saúde vocal é considerada um aspecto importante da saúde geral e qualidade de vida do professor, pois a voz é o seu principal instrumento de trabalho e importante recurso na relação professor/alunos, com implicações relevantes no processo ensino-aprendizagem. As alterações de voz (tais como rouquidão ou disfonia, afonia, dor ao falar, cansaço ao falar, falhas na voz, falta de projeção vocal e dificuldade para falar em forte intensidade) são responsáveis por um número significativo de queixas, licenças médicas, afastamentos e readaptações funcionais, representando prejuízos para o trabalhador professor, para a comunidade escolar e toda a sociedade ${ }^{(1-7)}$.

A literatura destaca a prevalência de alterações vocais em professores e aponta carências e/ou insuficiências em variados aspectos relacionados à voz e à saúde vocal docente: na percepção da própria voz, no preparo para o uso pro-

(1) Doutora em Saúde Pública pela Faculdade de Saúde Pública da Universidade de São Paulo - USP - São Paulo (SP), Brasil; Docente do Curso de Graduação em Fonoaudiologia e do Curso de Atualização em Saúde do Trabalhador da Universidade Metodista de Piracicaba - UNIMEP - Piracicaba (SP), Brasil.

Endereço para correspondência: Regina Zanella Penteado. Av. 41, 209/62, CJ, Rio Claro - SP, CEP 13501-190. E-mail: rzpenteado@unimep.br

Recebido em: 19/7/2006; Aceito em: 27/12/2006 fissional da voz, nos cuidados com a saúde vocal, na prevenção e na promoção da saúde ${ }^{(1,8-10)}$.

Estudos recentes ${ }^{(11-13)}$ sugerem que a relação entre saúde e trabalho, na escola, requer uma compreensão abrangente do professor e do seu processo saúde-doença, bem como das condições e organização do trabalho docente. Para isso, há que se buscar caminhos metodológicos que possibilitem evidenciar os sentidos latentes e a pluralidade de sentidos no trabalho, ou seja, ver o mundo pelos olhos dos próprios trabalhadores e colocar-se no lugar do outro a fim de procurar, pelos motivos do outro, compreender as suas razões, possibilidades de ação, critérios de decisão e compromissos entre objetivos conflitantes.

Apesar dos avanços nas pesquisas fonoaudiológicas, ainda são poucos os trabalhos que se propõem ao aprofundamento da investigação dos aspectos subjetivos, como as percepções e as construções de sentidos de professores acerca do tema da voz/saúde vocal ${ }^{(11,14)}$.

Tendo em vista contribuir para reflexões e propostas de ações voltadas para a promoção da saúde do trabalhador professor, é preciso melhor compreender as maneiras pelas quais a sociedade, por meio das relações de trabalho, da cultura e da qualidade de vida, influencia o processo saúde-doençacuidado de professores e, para tanto, faz-se necessário buscar conhecer as percepções que os trabalhadores professores têm acerca da sua voz, dos cuidados com a saúde vocal e as 
maneiras de interpretarem e de lidarem com os seus problemas vocais.

O objetivo da presente pesquisa é conhecer algumas percepções de professores acerca do processo saúde-doençacuidado relacionado à voz.

\section{MÉTODOS}

Trata-se de pesquisa qualitativa, uma vez que esta valoriza aspectos da subjetividade das pessoas e das especificidades dos seus grupos sociais e profissionais; do interesse pelo próprio corpo e pela saúde; das crenças, dos saberes, das percepções e da concepção que têm sobre a voz e o seu processo saúde-doença; enfim, dos modos (sócio, cultural e historicamente determinados) das pessoas interpretar e lidar com seu processo saúde-doença.

Foram sujeitos desse estudo 12 professores de Ensino Médio da rede Estadual de Ensino da cidade de Rio Claro/ SP (nove sujeitos do gênero feminino e três do masculino) que integraram a pesquisa de doutorado ${ }^{(5)}$ que originou o presente estudo, a qual contava com uma amostra estratificada proporcional de 128 professores (sujeitos numerados de $\mathrm{S} 1$ a S128) representativa das quatro escolas de Ensino Médio da cidade. A idade dos docentes variava entre 20 e 60 anos, com uma média de 39 anos, sendo que a classe de maior freqüência era de 40 a 49 anos. A maioria (57\%) lecionava em dois períodos e $32 \%$ lecionava em três períodos. A pesquisa foi aprovada pelo Comitê de Ética em Pesquisa da FSP/ USP (Prot. 588 - 13/11/2001).

Os 12 sujeitos integraram um grupo focal ${ }^{(9)}$, que foi o recurso metodológico utilizado para a coleta dos dados. O grupo focal é um grupo de discussões planejadas, orientadas por tópicos fornecidos pelo pesquisador e que, a partir da interação entre os participantes, em um ambiente permissivo e não-constrangedor, possibilita emergir percepções, valores, idéias e representações individuais e coletivas ${ }^{(15)}$.

A essência do grupo focal consiste na interação entre os participantes para a coleta de dados, que se dá a partir da discussão focada em temas ou tópicos específicos fornecidos pelo pesquisador. No grupo focal, são valorizados o discurso e as percepções dos sujeitos ${ }^{(15)}$. A forma de se obter os resultados se dá a partir da gravação das conversas realizadas e da transcrição do material gravado.

No presente estudo, as conversas e reflexões do grupo focal focalizaram o tema da voz/saúde vocal nos contextos de trabalho e de vida cotidiana, buscando-se identificar as percepções dos sujeitos acerca da própria voz e do processo saúde-doença-cuidado a ela relacionado.

A análise das transcrições possibilitou a identificação de temas e conjuntos temáticos que se referem às representações emergentes e as discussões apóiam-se nos conjuntos temáticos e desdobram-se, tendo em vista as contribuições para propostas fonoaudiológicas de promoção da saúde docente.

Os resultados referem-se a quatro conjuntos temáticos, apresentados com trechos de transcrição dos episódios discursivos a eles alusivos. Os trechos são apresentados seguidos pela identificação numérica dos sujeitos (entre parênteses) ex: $\mathrm{S} 1$ = sujeito 1 .

\section{RESULTADOS}

\section{O conhecimento e os cuidados com a voz/saúde vocal}

"Pode ver que eu estou aqui, mas estou sempre tentando não pigarrear de alguma maneira (engole a saliva).” (S45). "Tem hora que você tenta, tenta falar devagar, baixinho, você percebe que não resulta tanto, aí você continua; e essa (aponta o pescoço) é a conseqüência.” (S106). "A gente vai competindo com eles e vai elevando, elevando a voz (gesto de elevação com a mão)." (S116). "A questão de falar alto é uma questão de educação; nós somos educados a falar alto, a gritar! Então essa semana eu estava em sala de aula e tinha uns moços com o som ligado na rua, perto da papelaria. O som era tão alto que não dava pra gente ouvir nada dentro da sala, vibrava o prédio; agora você imagina essa gente dentro do carro com um som daquele, ninguém ouve nada!” (S114). "Eles gritam entre si, eles estão conversando aqui e gritam um com o outro; eles também não estão ouvindo bem, ficam com aquele walkman alto o tempo inteiro e vão perdendo sensibilidade auditiva.” (S116). "Para mim não é tanto o problema de barulho na sala de aula, é problema de falar muito mesmo, o meu problema é explicar, porque se são dez aulas, são dez aulas explicando. Então a agüinha, ali do lado, eu chego a tomar dois, três litros no dia; a agüinha ali do lado, porque eu falo muito!’' (S31).

\section{As preocupações e representações referentes ao processo saúde-doença}

"Eu tinha esse problema não é de hoje não, então você antigamente achava até que era normal. Agora você sabe que é um problema, que tem como estar tratando; porque antigamente nós achávamos até que era normal e continuávamos, né?" (S106). "Dá problema de calo nas cordas vocais (...) e, às vezes, quando você detecta o problema já é para o ponto de cirurgia." (S91). "Por isso que eu estou com medo, viu! Porque eu sou jovem ainda e acho que estou usando muito minha voz, usando muito. Eu não sei como vai ser no futuro, estou com medo. Estou com medo!” (S70). “Eu fiquei preocupada com tumor, porque o ano passado minha voz sumiu completamente; o ano passado fiz uma laringoscopia para ver se não tinha tumor. Eu falei: "eu posso ter um tumor", né?” (S116).

\section{As formas de perceber, identificar e interpretar os problemas vocais}

"No começo eu percebo que começou a alterar, estava ficando rouca; aí perdi a voz. Esse ano eu fiquei uns dois meses muda, fechei a boca e não falei mais. Eu fiquei muda! Fiquei um mês e meio ruim, tomando remédio porque não saía, inflamou tudo e eu não conseguia falar!" (S41). "Por ter essa coisa de falar alto, еи estou começando a ter dores, à noite; eu tenho dores aqui (mostra a região da laringe), não sei se são as cordas vocais que têm algum problema." (S112). "Eu percebo que eu estou com problema de voz quando eu começo a tossir; você começa a sentir que arde, mes- 
mo você ficando com a água do lado, quando (passa a mão no pescoço indicando dor na laringe). Mas, é a partir do momento que você começa a sentir arder, a sentir aquele incômodo que você percebe que está com um problema." (S45). "Um dia ou outro você fica meio assim (pigarreia); dá uma engasgadinha; é um negócio assim, quando você está falando e sai um mais fino, sabe? Mas até hoje eu não tive problema nenhum de voz." (S70). "O meu é isso, a voz. fica falhando, olha aí! (a voz falha na hora)” (S116).

\section{As maneiras de enfrentar os problemas vocais}

"Porque é aquela coisa, geralmente acontece isso: eu vou ver o que está acontecendo quando já surgiu o problema né? Então não é algo que a gente tem que tá, assim, procurando, tem que tá atento. Mas, é difícil, né?” (S91). "Com essa voz aqui (aponta o próprio pescoço) você fala uma coisa e as pessoas que estão perto de você (tampa as duas orelhas e sorri) né? Então, eu já tive problema de rouquidão, no início eu cheguei até a tirar licença, não conseguia falar. Hoje já estou habituada, minha voz é mal colocada e eu tenho um calo na corda vocal." (S48). "Você está habituada a falar em voz alta o tempo todo você está tão acostumada (gesto elevando as mãos) com seu tom de voz que você não consegue mais falar baixo; então não é só em sala de aula, você acaba forçando o tempo todo e é isso que vai estressando." (S45). "A gente percebe que até no dia-a-dia mesmo, as pessoas já estão acostumadas a ouvir tudo muito alto assistem televisão muito alto, colocam o walkman muito alto e, com certeza, na sala de aula eles vão falar alto também." (S91). "Eu já fiz tratamento com fonoaudióloga. No ano passado fiz uma laringoscopia para ver se não tinha tumor. Não tem! Então eu cheguei num ponto que vou continuar assim até eu me aposentar; porque não adianta, e eu não tenho paciência pra (trrrr - faz o exercício de vibração de língua), né? Isso daí eu não tenho paciência; de fazer o relaxamento, né? Às vezes, eu vou, no carro (trrrr - faz gesto de segurar o volante) até lá na escola. Mas eu não tenho paciência. Então eu já nem estou conseguindo fazer aquilo mais, entendeu? Mas, assim, no dia em que eu estou pior, evito falar muito e, no dia em que eu estou melhor, eu falo bastante e daí eu fico pior. Mas eu acho que vai ter que ser assim para o resto da vida." (S116).

\section{DISCUSSÃO}

No que diz respeito ao conhecimento acerca da saúde vocal (os cuidados com a voz), observa-se que os professores detêm noções, conhecimentos e informações correspondentes a alguns dos "cuidados" básicos sobre higiene/saúde vocal que versa sobre estilos de vida, hábitos e comportamentos favoráveis a uma boa saúde vocal. Eles sabem, por exemplo, que o pigarro é prejudicial e evitam pigarrear, preferindo engolir a saliva; eles procuram usar a voz em fraca intensidade e sabem que o desgaste vocal é decorrente do uso intensivo da voz em intensidade forte ou do grito; identificam questões sociais e culturais relacionadas ao uso da voz em forte intensidade, e ocorrência de competição sonora em diversos contextos coti- dianos; identificam questões didático-pedagógicas referentes ao modelo de ensino-aprendizagem em que se baseiam e sabem da necessidade de hidratação laríngea, bebendo água durante o uso profissional da voz. Na rotina diária, entretanto, essas noções e ideários não se concretizaram, o que coloca em xeque a hipótese de que os docentes não cuidam de suas vozes por falta de informação. Evidencia-se, assim, a necessidade de atenção, para outros fatores - da qualidade de vida, da subjetividade, da história, da cultura, das condições e da organização do trabalho docente - que interferem nas escolhas dos sujeitos e comunidades em relação aos seus cuidados de saúde. Há, portanto, que se buscar construir processos educativos que ofereçam espaço para a reflexão e a ação transformadora dos sujeitos em sua relação com a saúde, nos contextos cotidi$\operatorname{anos}^{(13)}$.

No tocante ao segundo conjunto temático, às preocupações e representações referentes ao processo saúde-doença vocal, nota-se um aumento da preocupação dos professores que, anteriormente, costumavam considerar a rouquidão como voz "normal", habitual e "natural", no contexto da docência e que hoje, entretanto, a interpretam como indicativa de problemas de saúde vocal e geral. Em outras palavras, a rouquidão, antes supostamente "ignorada" pelos professores, agora é por eles interpretada como uma doença grave ou distúrbio, na medida em que é associada à idéia de diagnósticos médicos de alterações orgânicas e patologias em estágios avançados. Seria o caso de "nódulos (calos) vocais", "tumores" ou "câncer de laringe" - sugestivos de prognósticos de tratamentos complexos, invasivos e agressivos como as intervenções cirúrgicas, que trazem sofrimentos, períodos de internação e de afastamento do trabalho e que suscitam sentimentos negativos, assustadores e amedrontadores nos professores $^{(11)}$.

Se, por um lado, isso representa um avanço em termos de "conscientização" e de educação em saúde da população docente, por outro, o fato do sujeitos os sinais de desgaste vocal ou de perda da qualidade vocal a partir de uma representação que os relaciona a problemas mais graves, indica que o processo saúde-doença vocal docente está imbuído de uma lógica clínica - e não àquela referente ao enfoque em voz profissional, que seria o mais apropriado. Isto, ao mesmo tempo em que ajuda a compreender algumas das razões pelas quais os professores se esquivam da procura por uma avaliação com um profissional especializado (ou demoram a fazê-lo), também sinaliza os resquícios das dificuldades das práticas fonoaudiológicas, em se desfazerem do aporte clínico e do foco na patologia e de se nortearem pela promoção da saúde, na sua relação com a qualidade de vida.

Sem subestimar ou banalizar a problemática dos distúrbios vocais em professores, sugere-se que, na medida do possível, as ações educativas fonoaudiológicas se abstenham do apelo dramático, na perspectiva de se valorizar recursos menos ameaçadores, agressivos e traumáticos, que contribuam para a desmistificação do caráter "assustador" e "amedrontador" atribuído à disfonia, pela categoria docente, e de se favorecer, aos professores, vivenciar processos de sensibilização para perceberem a voz como um recurso da relação homem-mundo, com implicações no campo pessoal, 
social e profissional; e a saúde vocal como um recurso aplicado à vida.

Quanto ao terceiro conjunto temático, referente à percepção e identificação de um problema de voz/saúde vocal, os resultados demonstram que os professores interpretam alguns indicativos/sinais/sintomas como significativos e representativos de problemas de saúde vocal; enquanto que outros desses indicativos, ainda que percebidos pelos docentes, são destituídos de importância e de significação e não remetem os sujeitos a interpretarem as suas condições de saúde vocal como problemáticas ou carentes de atenção e de cuidados.

Os professores demonstram dificuldades em perceber o seu processo saúde-doença e refletir sobre os sinais e sintomas vocais que apresentam. Isso pode ser indicativo de um quadro de dessensibilização ao próprio sofrimento e de deformação nas maneiras de perceber, de sentir, de interpretar, de significar e de enfrentar as experiências cotidianas - provavelmente, favorecido pela forma como o trabalho docente está organizado ${ }^{(11)}$.

Os indicativos/sinais/sintomas mais facilmente interpretados/significados em sua provável relação com problemas de saúde vocal são aqueles que provocam sensações físicas/ corporais de desconforto significativo, como o ardor e a dor ao falar, a tosse e as infecções de laringe, além da rouquidão e perda total da voz (mudez, afonia). Assim, os professores mostram-se pouco sensíveis para interpretar os indicativos de característica perceptivo-auditiva, evidentes na produção e na variação da qualidade vocal, especialmente em contextos de relações sociais conflitantes e de intensa demanda vocal - pigarro, engasgos, falhas e quebras da sonoridade na voz e a instabilidade fonatória, por exemplo, que, aqui, não foram interpretados como indicativos de problemas vocais.

O trabalho docente, muitas vezes, é revestido de representações que o caracterizam como sacerdócio ou missão, implicando doação, dedicação, disponibilidade, humildade, submissão, abnegação e sacrifício. Assim, frente à carga de compromissos e de responsabilidades que lhe são impostas no cotidiano, o professor, muitas vezes, prioriza o desempenho do seu trabalho, em detrimento de diversas experiências no campo da vida privada e da atenção, dedicação e cuidados com a própria saúde. Em outras palavras, muitas vezes não lhe restam tempo, energia ou oportunidades para refletir sobre seus desejos, expectativas, anseios, sonhos e projetos pessoais, nem para pensar as condições sob as quais se dá o seu trabalho, sua qualidade de vida, suas condições de saúde e os aspectos determinantes e intervenientes do seu processo saúde-doença. Então, a aparente perda de sensibilidade ao próprio sofrimento e a dificuldade de reconhecer e de identificar indicativos/sinais/sintomas de problemas vocais mais sutis poderia, aqui, ser apenas um dos componentes de um quadro mais abrangente e complexo que envolve as relações entre trabalho e saúde ${ }^{(11-13)}$.

Assim, sugere-se que as ações de promoção da saúde vocal de professores sejam organizadas de forma a contribuir para o desenvolvimento da capacidade de atenção, percepção e reconhecimento da própria voz e das suas qualidades, e das mais sutis variações, mudanças e transformações vocais pas- síveis de serem notadas, pelo professor, nas diversas relações sociais e nos variados contextos cotidianos de usos da voz, abrindo espaço para uma percepção mais ampla dos determinantes e intervenientes do processo saúde-doença docente.

Em relação ao quarto conjunto temático, nota-se que as estratégias de enfrentamento das alterações/problemas de voz são variadas e evidenciam-se dificuldades na busca de soluções efetivas e adequadas para a melhoria da saúde vocal.

Os professores resistem em buscar precocemente uma avaliação e, assim, o diagnóstico/avaliação acaba ocorrendo tardiamente, já em fases mais avançadas e agravadas do problema de saúde vocal. Ocorrem licenças de saúde sem a realização de um acompanhamento terapêutico adequado que possibilite, ao professor, identificar as suas reais necessidades e transformar a sua realidade. Notam-se estratégias de acomodação, de conformismo e tentativas de "naturalização" em relação aos problemas vocais ${ }^{(5)}$ - que podem ser indicativas de tendências pessoais e coletivas da categoria docente ou mesmo de experiências particulares anteriores com tentativas de tratamentos não concluídos e/ou mal sucedidos, as quais alertam para a necessidade de revisar os modelos e propostas terapêuticas da clínica fonoaudiológica. Por exemplo, o fato de, nas terapias, o fonoaudiólogo cobrar, dos professores, dedicação de tempo, paciência e disciplina na realização diária de relaxamentos, alongamentos e exercícios vocais, expectativa esta que se encontra, na maioria das vezes, além das possibilidades oferecidas pela organização do trabalho docente, levando ao insucesso da terapia e à frustração do profissional e do sujeito em acompanhamento.

Em suma, os resultados levam a considerar que problemas apontados na literatura, como a demora dos professores em buscar o atendimento fonoaudiológico, assim como o desinteresse e a falta de adesão a projetos ou propostas de ações em saúde vocal docente podem, na verdade, estar expressando defesas ou resistências no sentido de evitar depararem-se com sentimentos negativos despertados pelas representações que possuem acerca do processo saúde-doença vocal - e que acabam sendo reafirmadas pelo enfoque e apelo dramático das ações fonoaudiológicas tradicionais em saúde vocal.

Assim, as questões que envolvem o processo saúde-doença-cuidado em relação à voz do professor precisam ser trabalhadas, não somente no campo das escolhas e opções individuais de estilos de vida e comportamentos relacionados à voz, mas, também, no campo das discussões sobre o trabalho e a vida cotidiana, envolvendo, assim, toda a comunidade escolar ${ }^{(11)}$.

\section{CONCLUSÃO}

A investigação, acerca das percepções e das maneiras de professores lidarem com o seu processo saúde-doença-cuidado relacionado à voz, permitiu evidenciar distanciamentos, entre as necessidades docentes, e aquilo que as tradicionais ações educativas fonoaudiológicas em saúde vocal costumam oferecer.

A pesquisa aponta a importância de investimentos em 
processos de conhecimento, discussão, reflexão e reedição dos referenciais simbólicos, das representações e das concepções que os professores e os fonoaudiólogos possuem a esse respeito; bem como de revisão das ações para ampliação dos seus objetivos e focos, de maneira a englobar questões referentes a aspectos de organização do trabalho, de subjetividade e de qualidade de vida de professores.
Os professores e os demais profissionais envolvidos com a causa da saúde docente (especialmente o fonoaudiólogo) hão que ser sensibilizados, desde o seu processo de formação, para assumirem uma concepção de voz/saúde vocal como um recurso da relação homem-mundo aplicado à vida, um meio de expressão e comunicação intersubjetiva que tem implicações no campo pessoal, social e profissional.

\begin{abstract}
Purpose: The purpose of this research was to know teachers' perceptions about the health-disease process related to their voices. Methods: A qualitative research was carried out, using the focal group for data collection and content analysis for the organization of the teachers' perceptions into theme groups. Results: Four theme groups were identified: knowledge and care, preoccupations and representations, problem identifications and manners to face them. Conclusions: The study questions traditional educative actions in vocal health and confirms the need for professionals involved with the promotion of teachers' health to assume health as a resource applied to people's lives. They must enlarge their objectives and action focuses, including matters regarding work organization and daily life, subjectivity and quality of life, in order to better respond to the teachers' needs and ways to acknowledge and deal with the health-disease process.
\end{abstract}

KEYWORDS: Health promotion; Health education; School health; Voice; Voice quality; Voice disorders

\title{
REFERÊNCIAS
}

1. Centro de Referência em Saúde do Trabalhador. Coordenadoria de Controle de Doenças.(CEREST/CCD). Distúrbios de voz relacionados ao trabalho. Bol Epidemiol Paul. 2006;3(26):16-22.

2. Boneti G, Koslovski N. Qualidade de vida e a profissão professor. Vizivali Rev. 2005;4(1):62-75.

3. Carelli EG, Nakao M. Educação vocal na formação do docente. Fono Atual. 2002;5(22):40-52.

4. Fuess VLR, Lorenz MC. Disfonia em professores do ensino municipal: prevalência e fatores de risco. Rev Bras Otorrinolaringol. 2003;69(6):807-12.

5. Grillo MHMM, Penteado RZ. Impacto da voz na qualidade de vida de professore(a)s do ensino fundamental. Pró-Fono. 2005;17(3):321-30.

6. Williams NR. Occupational groups at risk of voice disorders: a review of the literature. Occup Med (Lond). 2003;53(7):456-60.

7. Dragone MLOS. Novos caminhos para os estudos sobre a voz do professor. Rev Fonoaudiol Brasil. 2001;1(1):43-50.

8. Vilkman E. Voice problems at work: A challenge for occupational safety and health arrangement. Folia Phoniatr Logop. 2000;52(1-3):120-5.

9. Roy N, Merrill RM, Thibeault S, Gray SD, Smith EM. Voice disorders in teachers and the general population: effects on work performance, attendance, and future career choices. J Speech Lang Hear Res. 2004;47(3):542-51.
10. Roy N, Merrill RM, Thibeault S, Parsa RA, Gray SD, Smith EM. Prevalence of voice disorders in teachers and the general population. J Speech Lang Hear Res. 2004;47(2):281-93.

11. Penteado RZ. Aspectos de qualidade de vida e de subjetividade na promoção da saúde vocal do professor [tese]. São Paulo: Faculdade de Saúde Pública da Universidade de São Paulo; 2003.

12. Schwarz K, Cielo CA. A voz e as condições de trabalho de professores de cidades pequenas do Rio Grande do Sul. Rev Soc Bras Fonoaudiol. 2005;10(2):83-90.

13. Gonçalves CGO, Penteado RZ, Silvério KCA. Fonoaudiologia e saúde do trabalhador: a questão da saúde vocal do professor. Saúde Rev. 2005;7(15):45-51.

14. Penteado RZ, Rossi D. Vivência de voz e percepções de professores sobre saúde vocal e trabalho. Saúde Rev. 2006;8(18):39-47.

15. Penteado RZ, Gonçalves CGO, Silvério KCA, Rossi D, Libardi A, Vieira TPG. Grupos Focais: possibilidades e aplicações para as pesquisas e práticas fonoaudiológicas. Rev Soc Bras Fonoaudiol. 2006;11(2):1248. 